\title{
A Discussion And Experiment On Incorporating History Into The Mathematics Classroom
}

Carryn Bellomo, University of Nevada Las Vegas, USA

Cassidy Wertheimer, East Career and Technical Academy, USA

\begin{abstract}
As a high school algebra teacher continuing as a student in a Master's of Mathematics Program, the author decided with the help of an advisor to see what effect incorporating history had on an Algebra II Honors course. The following paper includes a brief review of research, analysis of ways to incorporate history of mathematics into the classroom, examples of methods used in the classroom, and the effect this had on student and teacher learning and attitudes.
\end{abstract}

Keywords: Math History, Algebra II, Lesson Studies

\section{BENEFITS OF HISTORY IN MATHEMATICS EDUCATION}

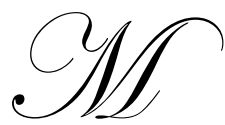

any authors suggest that incorporating the history of mathematics in the classroom leads to a heightened awareness and appreciation of mathematics, aids in looking at problems from a different perspective, and helps students understand why mathematics is important (Gulikers \& Blom, 2001; Kelley, 2000; Liu, 2003; Wilson \& Chauvot, 2000). When a student thinks about mathematics in general, they sometimes wonder why anyone would ever decide to solve equations or study trigonometry (Kelley, 2000). Introducing students to the history of mathematics provides them with a chance to see connections between subjects (Wilson and Chauvot, 2000). Students may also lack the connections between mathematics and the real world, and may benefit from exposure to how mathematical concepts developed over time (Liu, 2003). Perhaps by incorporating the history of mathematics, it will inspire students to explore mathematical connections within various disciplines (Gulikers and Blom, 2001).

In addition, a brief study of history may alleviate students' fears and help them see that some mathematical concepts were not conquered overnight (Kelly, 2000). For example, many students have a hard time understanding operations involving zero and negative numbers (Kelley, 2000), and may find comfort knowing mathematicians felt the same way for many years. In fact, these numbers were not fully recognized by western mathematicians until about 500 years ago (Kelley, 2000). Similarly, mathematicians throughout time have overcome difficulties and learned from their mistakes (Gulikers and Blom, 2001). This may help students realize that over time they too will understand concepts.

In addition to benefiting students, teachers using history of mathematics may also benefit from its incorporation (Liu, 2003). Teachers who have a good understanding of the history of mathematics are able to creatively pass this on to their students (Liu, 2003). Understanding the role of history may help teachers understand what they teach and why, thus improving their own teaching practices (Pengelley, 2002). Teachers who have an understanding of the progression of mathematics throughout history may use this information to guide them as they lead their students through such progressions (Wilson and Chauvot, 2000).

If the benefit to students and teachers is not enough, incorporating history in the classroom directly correlates to the National Council of Teachers of Mathematics (NCTM) Principles and Standards for School Mathematics published in 2000. The Nevada Mathematics Standards - which are similar in nature to standards 
posed in Principals and Standards for School Mathematics - include "Problem Solving, Mathematical Communication, Mathematical Reasoning, and Mathematical Connections" (Rheault, LaMarca, \& Brancamp, 2006; NCTM, 2000). Each of these four process standards can be enhanced in the classroom by incorporating the history of mathematics.

\section{INCORPORATING HISTORY}

Research suggests one of the best methods to incorporate history is to use it to introduce students to a given objective (Liu, 2003). This method was utilized most frequently in the classroom for the purpose of this study. Many lessons involved students reading a prepared summary; or at times, students were asked to research on their own. Also, to introduce or close a lesson, handouts on mathematicians throughout history were provided. On occasion, historical problems and methods were studied, worked on, and compared to current methods.

In each of these contexts, students used writing and classroom discussion to reflect on historical people or problems, summarize mathematicians' accomplishments, or compare methods used. New topics arose from student interest during investigations, so it is advised to be open and flexible. Specific example lessons are outlined below.

An example of incorporating history into a lesson was within a unit on Polynomials and Polynomial Functions. The lesson was on modeling polynomial functions using finite differences, specifically cubic polynomials, and a system of equations (Larson, Boswell, Kanold, \& Stiff, 2004). Students read a brief summary on Gauss which contained the famous Baby Gauss problem (Johnson, 1999).

The famous Baby Gauss problem refers to a proposed story of Gauss as a young student. When asked to find the sum of integers from 1-100, he did so in a quick time because he created 50 pairings of integers with a sum of 101 $(1+100,2+99,3+98, \ldots, 50+51)$ to find a solution of 5050.

Many students found the sum of the first 100 integers, but only a few came up with a solution that was not based on actually adding all of the numbers. After these students presented their solutions, Gauss' solution and the pattern $n(n+1) / 2$ were presented for comparison. This allowed the class to show algebraically that each correct pattern (or formula) yielded the same result. From there, the class looked at the degree of the polynomial and wrote a similar equation to model the pattern which led into the lesson on polynomials. The students were able to extend the Baby Gauss problem to write cubic polynomial functions.

In another example, after a lesson on the binomial expansion of $(x+y)^{n}$ involving Pascal's triangle, students were asked to research Pascal's background and summarize his accomplishments. After researching, the students were intrigued by the mystical hexagon. Upon further investigation and using Baragar's A Survey of Classical and Modern Geometries (2001), students investigated Pascal's Theorem and proof. To explore this proof, students had to recall many previously learned theorems and postulates from geometry.

Within the unit on Quadratic Functions (i.e. solving quadratic equations by finding roots), students were asked to read about Hypatia of Alexandria. Within the reading, students were asked to find 3 numbers less than 20 that satisfied a common algebraic problem among Greek mathematicians (Johnson, 1999).

The problem is stated, "Find an integer that is the sum of two squares and whose square is also the sum of two squares (Johnson, 1999).”

An example is 5 , since $5=1^{2}+2^{2}$ and $5^{2}=25=3^{2}+4^{2}$.

In addition to finding solutions to the problem, students were asked to further research Hypatia. This particular historical study provided many additional topics, such as the mathematics behind an astrolabe and Pythagorean triples. 
Students were asked to review a historical method used by al-Khwarizmi to solve the equation $x^{2}+21=10 x$ (Tabak, 2004). The students were asked to discuss how they thought this method compared to the quadratic formula. They then tried to follow his explanation to solve other problems.

Before beginning our study of rational equations and functions, students read a short story in a book entitled Marvels of Math: Fascinating Reads and Awesome Activities (Haven, 1998). This story is based loosely on a conversation with al-Khwarizmi that may have taken place, as written by Kendall Haven (1998). The students were able to follow the story that described the properties of zero and what happens when quantities are raised to the power of zero or divided by zero (Haven, 1998). Students were exposed to the concept behind asymptotes and could discuss unique properties of zero, including infinity.

After completing readings about mathematicians throughout history, the class would discuss interesting aspects on unknown or misunderstood concepts, and even requested additional information on related topics. Gulikers and Blom (2001) suggested, "history of mathematics can be applied in educational situations to bring dynamics into mathematics teaching and create a lively classroom atmosphere." Many times, it seemed there was a sense of interest in lessons that may not have been there without the historical connection. The incorporation of the history of mathematics seemed to create connections and appreciation of the material that may not have been present otherwise.

\section{OBSTACLES IN IMPLEMENTATION}

While incorporating history into the classroom, presenting historical perspectives while maintaining mathematical rigor proved to be difficult. Unfortunately in upper level courses (such as Algebra II Honors) teachers are not often given the freedom to fill the curriculum as they see fit, and many of the historical topics incorporated did not always involve the level of rigor expected in such a course. A brief discussion with administration of the benefits of including such material went a long way in providing the opportunity to, at times, veer off course.

One could argue that there is insufficient time to include historical objectives. To ensure no time is taken from the mathematics curriculum, history should not be an extra activity - it should be incorporated into lessons (Liu, 2003). This may save time in the end because properly integrating history can be a great method to reach students and keep them actively engaged (Wilson and Chauvot, 2000).

Classroom resources are not conducive to teaching history of mathematics. Historical references made in current textbooks are brief and isolated with anywhere from one sentence to two paragraphs of information. Problems that are included for students are often too easy or too difficult with brief (if any) connections made. Therefore, it is up to the teacher to supplement the material with their own background research and preparation.

Lastly, the amount of time it takes in planning historical lessons that link to classroom objectives can be significant. The internet quickly provides numerous lessons, readings, and teaching strategies. In addition, books, such as those by Johnson (1999) and Haven (2001), aid in lesson development. The effort is worth the reward, and research urges teachers to take it upon themselves to investigate historical topics (Gulikers and Blom, 2001).

\section{COMPARISON OF CLASSROOMS}

Two Algebra II Honors courses with similar demographics were studied during a twenty-seven week period. History was implemented in one class (denoted the 'history class') but not the other (denoted the 'control group'). The lessons incorporating the history of mathematics were not an everyday occurrence. Content was chosen based on historical topics believed to correspond to (or extend from) lesson objectives. Sample lessons and examples can be provided upon request. 


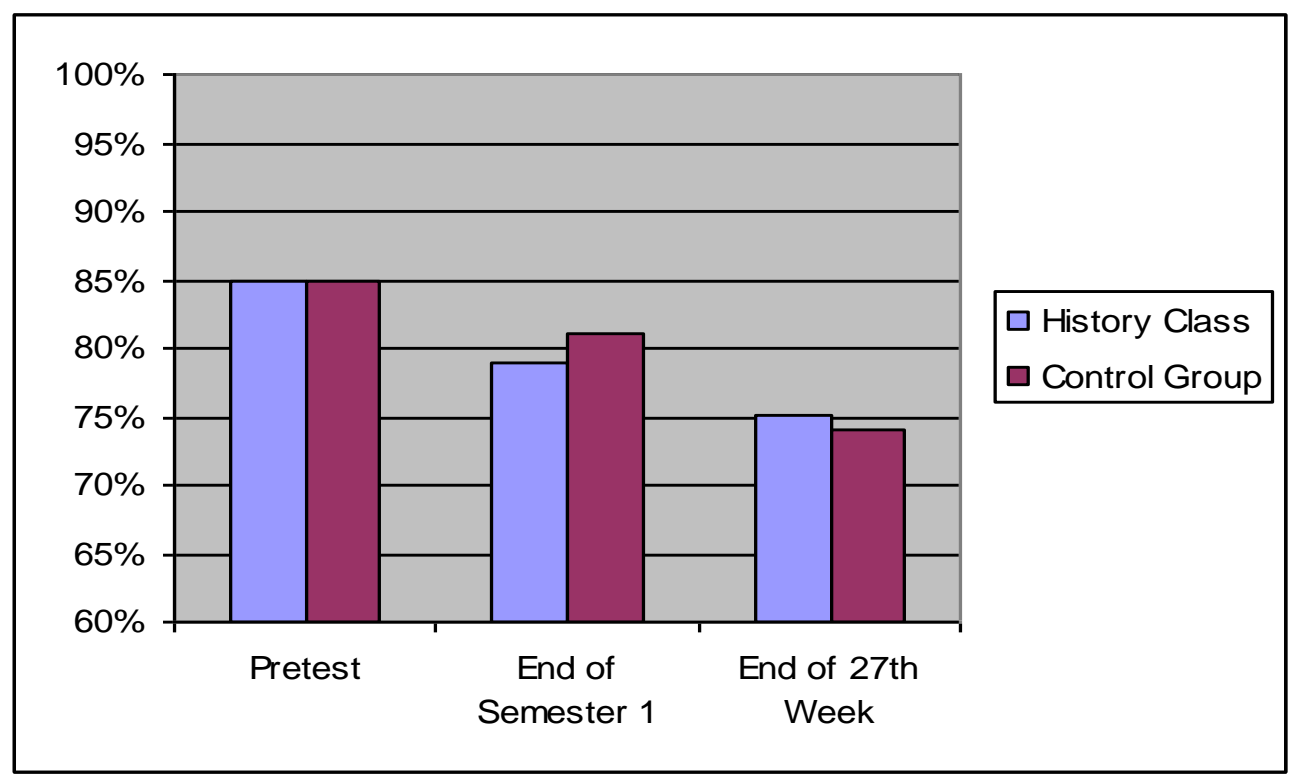

Figure 1. Comparison of average grades of students

The results in Figure 1 are a comparison of the average of student test scores for each class. The pretest was administered before instruction began. Each class began with an average pre-test score of $85 \%$. Also there is a comparison of the averages of semester one grades, where the control group was at a slightly higher average (81\%) then the history class (79\%). Finally, there is a comparison of the average class grades at the end of the study, when the history class has an average that is one percentage point higher than the control group.

Each year students are provided with a questionnaire for teachers to receive feedback about how the material and instruction meets their needs. The questionnaire form can be provided upon request. The students are asked to agree or disagree on a scale of one to five with the statements below:

1. Checking assignments in class improved my overall understanding of concepts.

2. Relating objectives to English improved my overall understanding of concepts.

3. Relating objectives to Science improved my overall understanding of concepts.

4. Relating objectives to Social Studies/History improved my overall understanding of concepts.

5. Participating in discussions with peers improved my overall understanding of concepts.

6. $\quad$ Reading about mathematics improved my overall understanding of concepts.

Figure 2 provides a summary of these ratings. In the statements relating objectives to various disciplines (Figure 2, Questions 2 - 4), more students from the history class agree (or completely agree) that relating objectives improves their understanding. Question 4, however, is somewhat discouraging, because the data indicates that more students from the history class disagree that relating objectives to history improved their overall understanding.

A high number of students in both classes agree that peer discussion (Figure 2, Question 5) improves their overall understanding of concepts. This supports the use of classroom discussion, a technique implemented in both classes. 


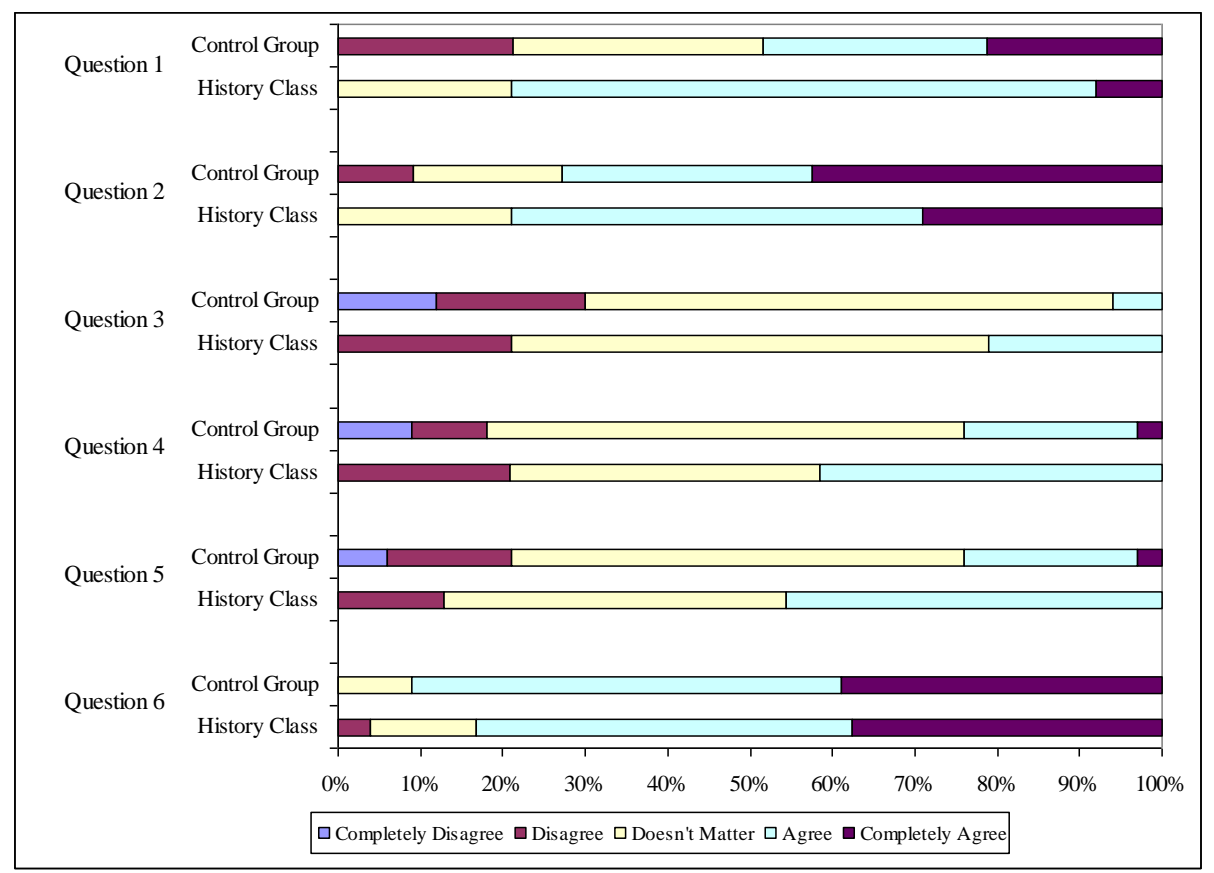

Figure 2. Comparison of results of student responses of questionnaire

For the most part, both classes agreed or completely agreed with the statement about reading (Figure 2 , Question 6). Hence, one cannot make conclusions based on reading about mathematics as it pertains to history.

In addition to the scaled questions above, the questionnaire asks for brief statements from the students regarding likes and dislikes in the mathematics classroom, and what they think about mathematics outside of the classroom. These freeform response questions were:

7. What have you liked about your past mathematics classes?

8. What have you liked in your current mathematics class?

9. What have you not liked about your past mathematics classes?

10. What have you not liked about your current mathematics class?

11. How do you notice or think about mathematics when you are not in class? For example, what do you notice when you are watching television or reading, with friends or family, etc? Please explain fully.

For questions 7 through 10, many of the responses from both the history class and the control group were similar in nature, generalizing teacher personality, style, and amount of course work required.

The last question, however, (Question 11) seemed to evoke a slight difference between the classes. Many of the responses from students in the control group (if they think about math at all) include descriptions of mathematical skills at the store, at work, in homework, etc. In contrast, a few student responses from the history class include "noticing patterns, using mathematics while playing games, seeing parabolas in shadows or curved pieces of material, and thinking of equations." Their responses seem to be more creative and reflective.

\section{CONCLUSIONS}

Upon comparison of the average grades of the students in the two classes, there is not a significant amount of difference to prove that incorporation of history of mathematics improves student performance. The incorporation may have affected the attitudes of the students in the history class based on the responses from the last question of the questionnaire; however, there was no concrete measure of this. While the responses did not relate to 
the history of mathematics, the students in the history class did seem to write about some connections they saw between mathematics and the world around them. This is the only measure of a general feeling the author had throughout the twenty seven weeks - that students in the history class developed more of an appreciation of mathematics and its connections.

By adding a new dynamic to lessons and approach in the classroom, the author notes the benefit to teaching. Incorporating history of mathematics proved to be a great teaching practice - there was a sense of excitement and interest in the history classroom. There may be two reasons for this. One reason could be the students actually were interested in the historical topic and saw some relevance to what was being discussed or investigated. A second reason might be that the teacher was more interested using this strategy in the classroom which affected her teaching.

In the long run, teaching practices were enhanced, and the author grew as a professional. Students benefited because this excitement and appreciation was passed on to them through lessons. Whether they feel the same excitement and appreciation is debatable. There is no question of the benefit of continued growth - seeking ways to enhance teaching practices and mathematical understanding. It is hoped that this exploration inspires others to do the same, and offers valuable suggestions for their classrooms.

\section{AUTHOR INFORMATION}

Cassidy Wertheimer is a high school mathematics educator who has most recently worked as the Mathematics Department Chair at a Project Based Learning-focused campus. She completed her MS in 2007 with a professional paper entitled, "Mathematics History in the Algebra II Classroom". Her current research interests include mathematical topics for infants and toddlers.

Dr. Carryn Bellomo is an Associate Professor at the University of Nevada, Las Vegas. She completed her Ph.D. in 1998 with dissertation titled "Mathematical Models of Tumors and Their Remote Metastases." Her early worked focused on applied mathematics, in particular mathematical biology. Since earning tenure, she has focused more of her attention on mathematics education, and how it relates to teacher training and alternative/enhanced teaching methods.

\section{REFERENCES}

1. Baragar, Arthur. (2001). A Survey of Classical and Modern Geometries: With computer activities. New Jersey: Prentice Hall.

2. Gulikers, Iris, \& Blom, Klaske. (2001). A Historical Angle, A Survey of Recent Literature on the Use and Value of History in Geometrical Education [Electronic Version]. Educational Studies in Mathematics, 47(2), 223-258.

3. Haven, Kendall. (1998). Marvels of Math: Fascinating reads and awesome activities. Colorado: Teachers Ideas Press.

4. Johnson, Art. (1999). Famous Problems and Their Mathematicians. Colorado: Teachers Ideas Press.

5. Kelley, Loretta. (2000). A Mathematical History Tour. Mathematics Teacher, 93(1), 14-17.

6. $\quad$ Larson, R., Boswell, L., Kanold, T. D., \& Stiff, L. (2004). Algebra 2. Illinois: McDougal Littel.

7. Liu, Po-Hung. (2003). Do Teachers Need to Incorporate the History of Mathematics in Their Teaching? Mathematics Teacher, 96(6), 416-420.

8. National Council of Teachers of Mathematics. (2000). Principles and Standards for School Mathematics. Reston, Virginia: National Council of Teachers of Mathematics.

9. Nevada Department of Education. (2006) Nevada Mathematics Standards: Integrating content and progess. Carson City, Nevada: Rheault, Keith W., LaMarca, Paul, \& Brancamp, David.

10. Pengelley, David J. (2002). A graduate course on the role of history in teaching mathematics. October 12, 2006, from http://www.math.nmsu.edu/ davidp/gradcourserolehist.pdf.

11. Tabak, John. (2004). Algebra: Sets, symbols, and the language of thought. New York: Facts on File, Inc.

12. Wilson, Patricia S., \& Chauvot, Jennifer B. (2000). Who? How? What? A Strategy for Using History to Teach Mathematics. Mathematics Teacher, 93(9), 642-645. 